\title{
Handbook of Paediatric Problems
}

\author{
Professor Pushpa Raj Sharma \\ "Handbook of Paediatric Problems" \\ Third Edition Makalu Publication House, \\ Dilli Bazar, Kathmandu, Nepal 2009724 \\ pp Price: Rs. 500/- (ISBN 978-9937-503- \\ 21-1) \\ The author, Professor Pushpa Raj \\ Sharma, of "Handbook of Paediatric \\ Problems" is a well known pediatrician \\ and a dedicated academician who has \\ been teaching and practicing paediatrics \\ since the last three decades.
}

The book has come a long way since

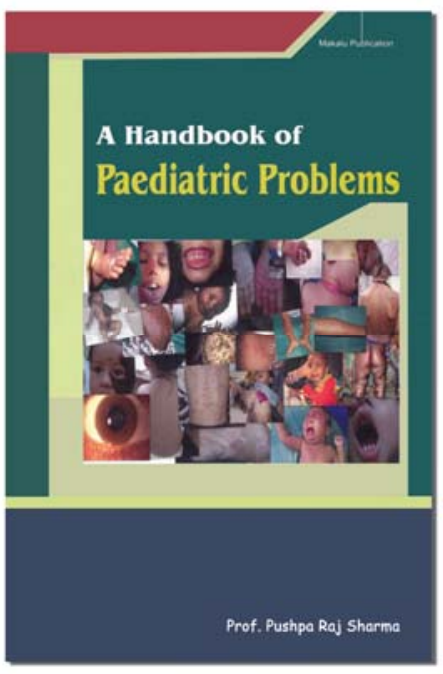

along with the exhaustive bibliography are proof of the tremendous effort that has been made while writing this book. Each chapter has highlighted sections with notes considered important by the author for readers and this is something students would need while preparing for exams.

Responding to the needs of the country and also trying to keep abreast with medical science, inclusion of chapters on adolescent health, preventive and social pediatrics with special emphasis on children in the war zone with relief efforts followed by a section on evidence based medicine make the book worth reading. it was first published in 1990, not only in size but also in content. It provides its intended readers, mainly undergraduate and postgraduate students, with updated knowledge which is practical and useful for managing patients in the hospital setting as well as reviewing the subject while studying for exams.

Separate sections on drug dosages, growth charts and immunization schedule, flow charts for approach to hypertension and septic shock and tables for presenting genetic diseases and inborn errors of metabolism are very useful for easy access and quick review. Appropriate emphasis has been given to problems commonly seen in this part of the world such as malnutrition, pneumonia with its complications and diarrhea. Problems that the author has come across over the years have been portrayed with excellent photographs and radiographs, which
To make the book affordable; illustrations are in black and white but this has made it difficult for the reader to appreciate important features especially those that depict changes in color.

Having colored photographs in the next edition and also increasing the font size of some flow charts and tables will make this excellent book even more userfriendly. Removing some editing errors and printing mistakes that have crept into this edition will further improve its quality.

This affordably priced book is a must buy for all medical undergraduates, paediatric residents and all doctors seing paediatric patients in Nepal.

Dr. Sudha Basnet, Associate Professor,

Department of Child Health, Institute of Medicine, Kathmandu, Nepal 